\section{IJ§ER}

ISSN: 2149-5939
International Journal of Socaial Sciences and Education Research

Online, http://dergipark.gov.tr/ijsser

Volume: 3(2), 2017

\title{
Sağık yöneticilerinde Liderlikte Özellikler Teorisi algılamaları
}

\section{The perceptions of theory of characteristics leadership in health care managers}

\author{
Şebnem Aslan ${ }^{1} \quad$ Seda Uyar² \\ Received Date: 03 / 09 / $2016 \quad$ Accepted Date: 12 / 11/2016 \\ $\ddot{\boldsymbol{O}} z$
}

Bu araştırma İ̧̧ Anadolu Bölgesindeki sağllk yöneticilerinde liderlikte özellikler teorisini araştırmak amactyla tasarlanmış bir araştırmadır. Araştırma nitel araştırma tekniklerinden görüşme tekniği kullanılmıştır. Araştırmada 8 sağlık yöneticisine ulaşılmış ve özellikler konusundaki değerlendirmeyi içeren 6 soru sorulmuştur. Araştırmanın sonucunda özellikler teorisinin liderlikte hali hazırda geçerliliği bulunan bir teori olduğu sonucuna ulaşılmakta ve liderlik tarzlarını etkilediği sonucuna varılmaktadır.

Anahtar Sözcükler: Liderlik, Liderlikte Özellikler Teorisi, Nitel araştırma, Görüşme yöntemi

\begin{abstract}
This study was designed to investigate research the theory of characteristics leadership in healthcare managers in Central Anatolia. In the study, the interview technic which is among the qualitative research technics was used. In the study, 8 healthcare managers were reached and they were asked 6 questions about the on the subject of characteristics evaluation. As a result of the study, it was concluded that the theory of characteristics was an availability processing theory in leadership and it affected the leadership styles.
\end{abstract}

Keywords: Leadership, Theory of Characteristics in Leadership, Qualitative study, Interview method.

\section{Giriş}

Sosyal bir varlık olan insanoğlu tarih boyunca yaşamını daha kolay sürdürebilmek ve tek başına üstesinden gelemeyeceği işleri başarabilmek için gruplar halinde yaşamaya ihtiyaç duymaktadır. Bu da grup içerisinde yönlendirici ve yönetici bir güce ihtiyacı kaçınılmaz kılmaktadır (Şencan vd., 2015). Çünkü hiyerarşik bir doğaya sahip olan insan bulunduğu ortamda doğal olarak liderliği gün yüzüne çıkarmaktadır (Cascio, 2010). Ayrıca değişimlerle başa çıkabilme ve değişiklere karşı oluşacak tepkileri elimine etmede liderlik etkili bir güç olarak görülmektedir (Decenzo ve Robbins, 2010). Liderlik gerek bireysel amaçları gerekse kolektif amaçları gerçekleştirmede de etkisi yadsınamaz bir kavram olarak karşımıza çıkmaktadır (Alder, 2002).

Liderlik süreci, etkileme ve etkilenme olayından oluştuğu için en az iki kişilik bir ilişkiyi zorunlu kılmaktadır (Paksoy, 2012). Liderin bir kitleyi belli amaçlar doğrultusunda sürükleyebilmesi için de marifet, enerji ve beceri sahibi olabilmesidir (Bush, 2007). Sahip olunması

${ }^{1}$ Prof. Dr., Selçuk Üniversitesi, Sağlık Bilimleri Fakültesi, Sağlık Yönetimi Bölümü, Sağlık Kurumları Yönetimi ve Organizasyonu Anabilim Dalı Başkanlığı, Konya, TURKEY,sebnemas@hotmail.com, sebnemas@selcuk.edu.tr, sebnemas@gmail.com.

${ }^{2}$ Arş Gör., Selçuk Üniversitesi, Sağlık Bilimleri Fakültesi, Sağlık Yönetimi Bölümü, Sağlık Kurumları Yönetimi ve Organizasyonu Anabilim Dalı Başkanlığı, Konya, TURKEY, seda inan@outlook.com 
Aslan, Ş., Uyar, S. (2017). Sağlık yöneticilerinde liderlikte özellikler teorisi algılamaları. International Journal of Social Sciences and Education Research, 3(2), 519-530.

gereken özellikler kimi araştırmacılara göre doğuştan gelirken kimi araştırmacılara göre de sonradan kazanılabilmektedir (Alder, 2002; Arslan ve Durmuş, 2013; Çetin ve Beceren, 2007).

Çalışmada öncelikle liderlik kavramından ve liderlik teorilerinden biri olan özellikler teorisinden kısaca bahsedilecektir. Görüşme tekniği ile ulaşılmış olunan 8 tepe yöneticisinin görüşleri arasındaki benzerlikler ve farklılıklar dâhilinde liderlik tarzı tartışılacaktır.

\section{Liderlik kavramı ve kapsamı}

Liderlik bir süreçtir ve bu süreçte birçok gücün bütünleşmesi ve bütünleşmesinden doğan bir etki söz konusu olmaktadır (Erçetin, 2000). Liderlik, belirli şartlar altında, belirli kişisel veya grup amaçlarını gerçekleştirmek üzere, bir kimsenin başkalarının faaliyetlerini etkilemesi ve yönlendirmesini kapsamaktadır (Koçel, 2011). Ayrıca belli bir amaç doğrultusunda kenetlenmiş bir topluluk için gerekli olan bir güç olarak da nitelendirilmektedir (Arslan ve Durmuş, 2013). Söz konusu liderlik davranışının temelinde liderin sahip olduğu öz inancı sayesinde peşinden sürüklemiş olduğu kitlenin de güvenini almış olması yatmaktadır (Cheong vd., 2016). Sonucu değiştiren kişi olarak ifade edilen lider (Baltaş, 2007), bir grup insanı belirli amaçlar etrafında toplayabilme ve bu amaçları gerçekleştirmek için onları harekete geçirebilme, etkileyebilme bilgi ve yeteneklerine sahip olmalıdır (Zel, 2001; Robbins ve Judge, 2012). Grup içerisinde rehber olarak tanınan lider, takipçilerini daima motive etmekte, risk almalarını sağlamakta ve sorumluluk almalarına yardımcı olmaktadır (Cheong vd., 2016).

Cascio (2010) liderliği, liderin stratejik vizyonunu başarıyla uygulayabildiği, kritik sorunlar çözümünde yönetim kademelerini geliştirebildiği ve bilinçli stratejik liderlik planlamaları yapabildiği bir özellik olarak tanımlarken, Yukl (2013) kararlı olma, insanları anlama ve insanları bir arada tutma süreci olarak görmektedir.

Liderliğin doğuştan geldiği yani liderin gücünün içinde olduğunu savunan çalışmalara karşın liderliğin sonradan gerek sosyal çevrede gerekse eğitim ile kazanıldığı görüşü de söz konusu olmaktadır (Alder, 2002; Arslan ve Durmuş, 2013). Hâkim olan görüş ise lider doğulamayacağı fakat bireyin liderliğe yatkın olabileceği ve dış faktörlerden etkilenerek liderlik özelliklerini daha da pekiştirebileceği yönünde olmaktadır (Çetin ve Beceren, 2007). Geleneksel liderlik teorilerine bakıldığında liderlik, liderin fiziki yeteneklerinin yanı sıra kişilik özelliklerinin de ifade edildiği bir kavram olarak karşımıza çıkmaktadır (Çetin ve Beceren, 2007).

\subsection{Liderlikte özellikler teorisi}

1930 ve 1940 yılları arasında liderlikle ilgili yapılmış olan çalışmalarda liderliğin yapısal özellikleri, kişilik, yetenek/beceri ve fiziki özellik olmak üzere üç temel grupta toplandığı görülmektedir (Özer 1997). Özellikler yaklaşımı olarak tanımlanan bu teoride bir kişinin lider olarak kabul görmesi sahip olduğu birtakım özelliklere bağlı olmaktadır (Çetin ve Beceren, 2007). Liderin lider olarak doğacağ görüşü özellikler yaklaşımının temelini oluşturmaktadır (Nahavandi, 2000). Özellikler Teorisi olarak bilinen Büyük Adamlar Teorisi, liderlerin doğuş$\tan$ gelen bazı özellikleri sayesinde olağanüstü işler başardığı düşüncesine dayanmaktadır (Northouse, 2001).

Özellikler yaklaşımına göre liderlerin taşıması gereken genel ve ortak bir takım özellikler bulunmaktadır (Lee ve Chang, 2006). Bu yaklaşım kişiyi lider yapan özeliklerin neler olduğu veya bazı kişilerin niçin etkin bir lider konumuna gelirken, diğer kişilerin bundan mahrum olduklarını kişisellikten kaynaklanan farklılıklarla açıklama fikrine dayanmaktadır (Bayram, 
Aslan, S.., Uyar, S. (2017). The perceptions of theory of characteristics leadership in health care managers. International Journal of Social Sciences and Education Research, 3(2), 519-530.

2013). Yani söz konusu yaklaşımda süreci etkileyen en önemli faktör olarak sahip olunan liderlik özellikleri görülmektedir (Keçecioğlu, 1998). Örneğin, liderin izleyicilerinden farklı olarak yaş, cinsiyet, yakışıklılık/güzellik, görünüm gibi fiziki özelliklerinin yanında hem zekâ, bilgi, kararlılı, güzel konuşma gibi yeteneklere hem de samimiyet, dürüstlük, özgüven gibi kişilik özelliklerine sahip olması gerekmektedir (Yukl, 2013). Bu özelliklerin yanında empati gücü, vizyon, dinleyici olunması ve daima çözüm odaklılık liderlik kapsamı içerisinde yer almaktadır (Barling vd., 1996; Ireland ve Hitt, 1999; Russell ve Stone, 2002).

Söz konusu bir lideri izleyicilerinden ayırt eden özellikler arasında güvenilir olması, yönetme yeteneği, karizmaya sahip olmasl, değişikliklere ayak uydurmast, strateji geliş̧tirebilmesi, bilgi toplayabilmesi ve cesaretliliği yer almaktadır (Çetin ve Beceren, 2007). Sıralanan bu özellikler kişide mevcut olduğu durumda lider olabilmesi söz konusu olmaktadır. Aksi takdirde yalnızca bir karizmaya sahip olma belli bir kitleyi peşinden sürüklemek adına yetersiz görünmektedir (Conarroe, 1989). Newstorm ve Davis (1993), liderlik olgusunu tanımlamada etkileme/destekleme, gönüllü çaba ve başarı hedefi gibi özelliklere değinirken, Şencan ve arkadaşları (2015) liderin takım ruhuna sahip olmasl, vizyona sahip olması ve bunu izleyicilerine benimsetmesi, öngörülü olması, yüksek motivasyon sahibi olması ve iletişim becerisine sahip olması gerektiğini ileri sürmektedir. Lunenburg (2011) ise sahip olunması gereken özellikler içerisinde özellikle kurum üyelerini ikna etme ve çalışanlara ilham verme, takım ruhunu aşılama gerekliliğini vurgulamaktadır. Herhangi bir insandan daha farklı, daha değişik, daha fazla, daha renkli, daha derin bir kapasiteler bütününe sahip olmak liderliğin en kestirme tarifi olarak görülmektedir (Fındıkçı, 2012). Çünkü liderlik olgusunun bazı yetenekleri gerektirdiği yadsınamayacağı gibi kişinin sahip olduğu özellikler de onun lider olmasını sağlamaktadır (Arslan ve Durmuş, 2013). Liderin takipçisi olduğu grup üzerindeki etkililiğinin değerlendirilmesi liderin çallşkanlık, olumluluk, duyarlılık, sertlik, samimiyet ve sorun çözücülük gibi sergilemesi gereken bir takım kişisel özelliklere bağlı bulunmaktadır (Uğurlu ve Hovardaoğlu, 2011). Belli bir kitleyi peşinden sürüklemeyi hedeflemiş bir lider, takipçilerinin istek ve heyecanlarını kullanarak onları doğru hayaller gerçekleştirmede yönlendirmelidir (Allix, 2000).

Afkhamive arkadaşları (2007) liderliği enerji, iletiş̧im ve amaçlara ulaşma kararlılı̆̆ı olarak görmektedir. Ayrıca liderlik, adalet, eşitlik, dürüstlük gibi değerlerle ilgilenmeyi gerektiren bir olgu olarak da tanımlanmaktadır (Açıkalın, 2000). Schermerhorn (1993) liderliğin en önemli karakteristik özelliği olarak sahip olunması gereken bir vizyon üzerinde vurgu yaparken, Kirkpatrick ve Locke (1991) mesleki bilgi, enerji ve iletişim üzerinde durmuşlardır. Kavrakoğlu ve arkadaşları (2002) kurum içerisinde liderin kullanabileceği en etkili iki özellik olarak iletişim ve motivasyondan bahsetmektedir. Kouzes ve Posner (2002) ise bir liderin takipçilerinin risk almalarını sağlamaları için güvene dayalı bir ilişkinin olması gerektiği üzerinde durmaktadır.

\section{Yöntem}

Bu araştırma Türkiye'deki liderlikte hangi özelliklerin tepe yönetiminde (liderlerinde) bulunduğunu araştırmak üzere tasarlanmış liderlikte özellikler teorisini araştırmak amacıyla yapılan bir çalışmadır.

Araştırma nitel araştırma tekniklerinden görüşme tekniği kullanılmıştır. Araştırmada İç Anadolu bölgesindeki 2 ilden ve 8 hastaneden 8 sağlık yöneticisine ulaşılmış ve kültürel değerlendirmeyi içeren 6 soru sorulmuştur. Katılımcılar, Konya ve Eskişehir olmak üzere İç 
Aslan, Ş., Uyar, S. (2017). Sağlık yöneticilerinde liderlikte özellikler teorisi algılamaları. International Journal of Social Sciences and Education Research, 3(2), 519-530.

Anadolu Bölgesindeki özel hastanedeki hastane direktörü, başhekim, genel müdür, hastane yönetim kurulu başkan yrd., gibi tepe yöneticilerinden oluşmaktadır. Örneklem seçiminde olasılıklı olmayan yöntemlerden biri olan gönüllülerin katılımından oluşan yönteme başvurulmuştur.

Görüşme tekniği, araştırmacı ile araştırmanın öznesi konumunda yer alan kişi arasında geçen kontrollü ve amaçlı sözel iletişim biçimi olarak tanımlanmaktadır (Patton, 1990). Söz konusu teknik ile amaçlanan hedef kişiye (kişilere) araştırma konusu ile ilgili sorular yönelterek hedef kişinin (kişilerin) öznel düşünce ve duygularını sistemli olarak öğrenmek, anlamak ve tanımlamaktır (Kvale,1996).

Araştırmada kullanılan sorular ulusal ve uluslararası literatürün taranmasıyla elde edilen soru havuzundan (Aslan, 2013; Bennis, 1959; Cheng, Chou, Wu, Huang, \& Farh, 2004; Kağıtçıbaşı, 2000; Kozan, 1993; Likert, 1979; Tannenbaum, Kimberly, \& Scott, 1998) seçilmiştir.

\section{Bulgular}

Soru 1: "Kendi sektörünüzde iyi bir lider sizce en çok hangi özelliklere sahip olmalıdır?"

Katılımcı 1. “...iletişsimi güçlü.”

Katılımcı 2. “...zeki... Teknik bilgiye sahip...”

Katılımcı 3. “...etkin performans yöneten, ...hakkaniyetli... eşit davranan...”

Katılımcı 4. “...etik, ahlakll... etkin iletişimci....kendine güvenen ...”

Katılımcı 5. “... takım odakll, güvenilir ...problem çözücü ”

Katılımcı 6. “...iletişsimi güçlü... Empati yapabilen...”"

Katılımcı 7. “...ahlaki değere sahip...etkin iletissim sağlayan, ...empatik davranabilen...”

Katılımcı 8. “...takım çalışmasına dayalı...”

Soru 2: "Çalışanlarınızı hangi yönünüzle daha çok etkilediğinizi düşünüyorsunuz?”

Katılımcı 1. "Hümanist olmam..."

Katılımcı 2. “... güvenilir olmam ...astların fikirlerini almam...”

Katılımcı 3. "...emeğe saygı duymam, hakkını vermem ...”

Katılımcı 4. “...astların önünü açmam...”

Katılımcı 5. “... Çalı̧̧anlarakoçluk yapmam..."

Katılımcı 6. "Dürüstlüğüm, iş disiplinli olmam..."

Katılımcı 7. "yetki vermem ...inisiyatif kullandırtmam...güçlü iletişim yönüm..."

Katılımcı 8. “...mütevazi kişiliğim,astlarımıdinlemem, çözüm odaklı olmam....”

Soru 3: "Astlarınızdan sizi tanımlamalarını isteseydik nasıl tanımlarlardı?"

Katılımcı 1. "Yapıcı...Kendilerine değer veren ...Destekleyen ...Yetki devreden ..."

Katılımcı 2. "Disiplinli ...güvenilir, empatik..." 
Aslan, Ş., Uyar, S. (2017). The perceptions of theory of characteristics leadership in health care managers.

International Journal of Social Sciences and Education Research, 3(2), 519-530.

Katılımcı 3. “... Babacan ... Dinleyen, ...Yol gösteren ...”

Katılımcı 4. “... Korkulan ama babacan....”

Katılımeı 5. “... disiplinli... kurallara uyulmasint isteyen ..."

Katılımeı 6. "kuruma katkı să̆layan..."

Katılımeı 7. “...sert ...otoriter..."

Katılımeı 8. “...liyakatli...”

Soru 4: "Tüm kişilerin sahip olmadığı, yalnızca lider olabilecek kişilerin sahip olduğu birtakım özellikler önem sırasıyla nelerdir?"

Katılımcı 1.: “... karizmatiklik... teknik bilgi... zeka ... disiplin ...Güvenilirlik ...”

Katılımcı 2.: “...çalışkanlık ...dürüstlük ve tutarlılık...”

Katılımcı 3. “...İkna gücüne sahip olma ...iyidiksiyonu olma...”

Katılımcı 4. “...Babacanlık...Tutku ...sorun çözebilme...”

Katılımcı 5. “...Zeka...fiziksel enerji,geniş bir vizyona sahip olma...."

Katılımcı 6. “...zeka ...enerji ....empati yeteneği olan ...ikna edebilme...”

Katılımcı 7. “... vizyonerlik...iletişsime ve değişime açık olma,takım ruhuna sahip olma...”

Katılımcı 8. “...zeka...”

Soru 5: "Başarılı liderlerin sahip olması gereken bir özellik, liderin önce kendi rüyasını sonra da takipçilerinin rüyalarını gerçekleştiren kişi olmasıdır şeklinde bir görüş ileri sürülmektedir. Bu görüşe katılıp katılmadığınızı nedenleriyle yorumlayabilir misiniz?"

Katılımcı 1.: “...kendi vizyonumuzu gerçekleştiriyorum ama takipçilerim için bir şey yapmiyorum."

Katılımcı 2. “...bir lider rüyasını gerçekleştirmek isterse diğer çalı̧̧anların rüyası ile birleştirmelidir..."

Katılımcı 3.: “...Kendi rüyasını gerçekleştirmeli yöneticiler, aksi durumda ekibine o güveni veremezler..."

Katılımcı 4. “... Çalışmak önemlidir. ... hayalin gerçekleşmesi doğru karar vermeyle alakall...”

Katılımcı 5. “...liderlerin rüyalarıyla astlarınki uyumlu olmalıdır.”

Katılımcı 6. “...liderlerin rüyaları ve takipçilerin rüyalarıyla uyum içerisinde olmalıdır. ”

Katılımcı 7. "...lider kendisinin rüyasını gerçekleştirirken birlikte çalıştığı takım arkadaşlarının hayallerini de gerçekleştirme çabasında olmalı."

Katılımcı 8. “... Karşısındakinin duygu ve düşüncelerini doğru anlamak ve hissetmek gerekir."

Soru 6: "Başarılı liderlerin sahip olması gereken bir özellik, liderin kendi becerilerinin farkında olması ve bilgisini ve becerisini kullanmayı bilmesidir şeklinde bir görüş ileri sürülmektedir. Bu görüşe katılıp katılmadığınızı nedenleriyle yorumlayabilir misiniz?” 
Aslan, Ş., Uyar, S. (2017). Sağlık yöneticilerinde liderlikte özellikler teorisi algılamaları. International Journal of Social Sciences and Education Research, 3(2), 519-530.

Katılımcı 1. "kendinizi çok iyi bilmeniz, tanımanız, artılarınızın neler olduğunun farkında olmanız, öne çıkarmanız, eksilerinizi de bir an önce giderecek tedbirleri almanız gerekir..."

Katılımcı 2. "...liderin kendi becerilerinin farkında olması gerekir. Bu farklılı̆̆ı da çalıştırmış olduğu organizasyonuna yansıtmalı diye düşünüyorum.”

Katılımcı 3. "iyi bir liderin mutlaka bildiği şeyleri kullanması, kullanıma geçirmesi ve başarılı olması gerekir."

Katılımcı 4. "Hayatını boyunca her zaman sahada olunmalıdır..."

Katılımcı 5. "Lider yaptığı ve yönettiği işi iyi bilmeli...Yoksa başarısız olursun..."

Katılımcı 6. "Lider bilgisinin farkında olmalı ve uygulamaya aktarabilmelidir. ..."

Katılımeı 7. “...lider kendisini keşfettikten sonra bunu harekete geçirmelidir. Kendini bilemeyen bir lider, ekibinin neler yapacağını da bilemez. ..."

Katılımcı 8. “...her lider kendinde ne noktalarda bir cevher olduğunu ne noktalarda eksiklerin olduğunu tartabilmelidir..."

\section{Sonuç}

$\mathrm{Bu}$ araştırma özellikler teorisinin günümüzde hala uygulamada söz konusu olup olmadığını araştırmaya yönelik yapılmıştır. Ayrıca hangi özelliklerin tepe yönetiminde bulunduğunu araştırmak üzere tasarlanmıştır.

Araştırmanın sonucunda, "Kendi sektörünüzde iyi bir lider sizce en çok hangi özelliklere sahip olmalıdır?" sorusuna yöneticiler tarafından verilen ortak cevap; iletişim yeteneğine ve ahlaki değerlere sahip olma şeklindedir. Bu özelliklere ilaveten liderin takım başarısına inanması, objektif olması, ortalamanın üzerinde zekâya sahip olması, güvenilir ve hakkaniyet sahibi olması gerektiği vurgulanmıştır.

Yöneticilere "Çalışanlarınızı hangi yönünüzle daha çok etkilediğinizi düşünüyorsunuz?" sorusu yöneltilmiş ve yöneticilerin sahip oldukları özellikler arasında çalışanlara fikirlerini sormaları, onların düşüncelerine önem vermeleri oluştur. Ayrıca yöneticilerin mütevâzi ve hümanist olmaları, disiplinli çalışmaları, çözüm odaklı davranmaları ve daima iletişime açık olmaları da çalışanlarını etkiledikleri özellikleri olarak görülmüştür.

“Astlarınızdan sizi tanımlamalarını isteseydik nasıl tanımlarlardı?” sorusunda ortak cevap yöneticilerin astlarına babacan davranmaları ve disiplinli olmaları şeklindedir. Bu özelliklere ilaveten sahip olunan yapıcı özellik, astları destekleme, güvenilir olma, astını dinleme, otoriter tavır sergileme ve liyakat esaslı çalışma özellikleri de yöneticilerin sahip oldukları özellikler olarak belirtilmiştir.

Araştırmada yönetilmiş bir diğer soru "Tüm kişilerin sahip olmadığı, yalnızca lider olabilecek kişilerin sahip olduğu birtakım özellikler önem sırasıyla nelerdir?” şeklindedir. Yöneticilerin vermiş oldukları cevaplarda ortak özellikler ikna gücü ve iletişim yeteneği şeklinde belirtilmiştir. Bu iki özellikle birlikte disiplin, güvenirlilik, düzgün bir diksiyon, çalışkan olma, samimiyet, sağduyu, empâti, değişime açıklık ve takım ruh ile hareket etme de belirtilen diğer özelliklerdir.

"Başarılı liderlerin sahip olması gereken bir özellik, liderin önce kendi rüyasını sonra da takipçilerinin rüyalarını gerçekleştiren kişi olmasıdır şeklinde bir görüş ileri sürülmektedir. $\mathrm{Bu}$ 
Aslan, Ş., Uyar, S. (2017). The perceptions of theory of characteristics leadership in health care managers. International Journal of Social Sciences and Education Research, 3(2), 519-530.

görüşe katılıp katılmadığınızı nedenleriyle yorumlayabilir misiniz?” sorusuna yöneticilerin çoğunluğu hem fikir olarak katılmaktadır. Bazı yöneticilere göre liderin takipçilerinin güvenini kazanabilmek adına kişinin kendi rüyasını öncelikle gerçekleştirmesi önem arz ederken, bazı yöneticilere göre de liderin kendi rüyası ile takipçilerinin rüyalarını birleştirmesi gerekmektedir. Diğer yandan bu görüşe katılmadıklarını ileri süren yöneticiler ise yalnızca kendi rüyalarını gerçekleştirdiklerini fakat takipçileri için bir şey yapmadıklarını ifade etmektedirler.

"Başarılı liderlerin sahip olması gereken bir özellik, liderin kendi becerilerinin farkında olması ve bilgisini ve becerisini kullanmayı bilmesidir şeklinde bir görüş ileri sürülmektedir. Bu görüşe katılıp katılmadığınızı nedenleriyle yorumlayabilir misiniz?” sorusu yöneticilere yöneltilen bir diğer sorudur. Yöneticilere göre bir lider alanında bilgi sahibi olduğu sürece güce sahip olmakta ve başarı sağlamaktadır. Ayrıca sahip olduğu bilgiyi de hitap ettiği kitleye yansitabilmeli, aktarabilmelidir.

Araştırma sonucunda yöneticiler başarılı bir liderde olması gereken en önemli özellik olarak iletişim üzerinde durmuşlardır. Ayrıca kendilerinin de kurum içerisinde takipçileri tarafından etkin iletişime sahip oldukları şeklinde atıf gördüklerini ifade etmişlerdir. Liderin hem örgütsel hem de bireysel manada iletişim yeteneklerine sahip olması ve bunu ihtiyaçlar doğrultusunda kullanıyor olması özellikler teorisine göre olması gereken özelliklerden biri olarak ifade edilmektedir (Afkhami vd., 2007).

Aynı zamanda zeka, empati, disiplin, ikna gücü, karizma da liderin sahip olması gereken özellikler olarak belirtilmiştir. Bunun yanında astlarına karşı iyi bir dinleyici olma, çözüm arayıcı olma, takım ruhu içerisinde ortak hedefler peşinden gitme de lider olacak kişilerde bulunması gereken nitelikler olarak görülmüştür. Özellikler yaklaşımı kuramına göre yöneticilerin sıralamış oldukları bu özelliklere bir lider gruptaki bireylerden (izleyicilerden) daha fazla sahip olmaktadır (Barling vd., 1996; Ceylan, 1997; Conarroe, 1989; Lunenburg, 2011).

Ayrıca araştırma sonucunda bir liderin hem kendi hem de takipçilerinin rüyalarını gerçekleştirmeleri başarı için gerekli görülmekte ve bu başarının da yine empati ve çok çalışmakla olabileceği ifade edilmiştir. Literatür incelendiğinde özellikler yaklaşımında da lider sahip olduğu birçok değeri ortak hayalleri gerçekleştirme pahasına kullanabilmelidir (Rost, 1991). Liderin sahip olduğu ve gerçekleştirmeyi arzu ettiği hayaller ancak sahip olduğu yetki ve enerjiyi çalışanlar üzerinde motivasyona dönüştürebilmesi ile mümkün olabilmektedir (Davis, 1988; Hedlund vd., 2003).

Araştırma sonucunda liderlerin başarılarını etkileyecek diğer bir husus sürecin gerektirdiği beceriye sahip olması ve bunu da en etkili şekilde yönetebilmesidir. Özellikler yaklaşımına göre liderin hem sahip olduğu becerilerin farkında olması hem de eksik olduğu noktalar üzerinde eğilim göstermesi kendini ve takipçilerini yönetebilmede önemli görülmektedir (Eren, 1998).

Sonuç olarak günümüz liderleri, özellikler teorisinin kısa tanımı olabilecek "lideri lider yapan unsur, onun özellikleridir” (Aslan, 2013) ifadesini sürdürmektedirler. Hem sahip oldukları birçok özelliğin kendilerinin lider olmalarında etkili olduğunu belirtmiş hem de bu özellikler sayesinde takipçilerinden liderlik atfı aldıklarını ifade etmişlerdir. Ayrıca günümüzdeki liderlik anlayışında özellikle iletişim ve zekâ üzerinde vurgu yapıldığı da görülmektedir. 
Aslan, Ş., Uyar, S. (2017). Sağlık yöneticilerinde liderlikte özellikler teorisi algılamaları. International Journal of Social Sciences and Education Research, 3(2), 519-530.

\section{Kaynakça}

Açıkalın, A. (2000). “İlköğretim Okulu Yöneticilerinin Dönüşümcü Liderlik Özellikleri Ve Empati Becerileri Arasındaki İlişki (Ankara İli Örneği)”. Gazi Üniversitesi Eğitim Bilimler Enstitüsü, Yayınlanmamış Yüksek Lisans Tezi, Ankara.

Afkhami, M., Eisenberg, A., Vaziri, H. (2007). Seçenekler Yaratmak: Kadınlar için Liderlik Eğitimi El Kitabı. İstanbul: Kadın Emeğini Değerlendirme Vakfı (KEDV) Yayınları.

Alder, H. (2002). Bir Lider Gibi Düşünün. (Çev: Halime Misge Kurşun). İstanbul: Kariyer Yayıncılık.

Allix, M. N. (2000). Transformational Leadership, Democraticor Despotic ?. Educational Management \& Administration, 28(1).

Arslan, H., Durmuş, Ö. (2013). İlköğretim Öğrencilerinde Görülen Liderlik Davranışlarının Araştırılmas1. International Journal of Social Science, 6(1), 207-228.

Aslan, Ş. (2013). Geçmişten Günümüze Liderlik Kuramları (Sağlık Yönetimi Bakış Açısıyla). Konya: Eğitim Yayınevi.

Aykan, E. (2002). Girişimcilik ve Girişimcilerin Liderlik Davranışları (Kayseri'de Bir Uygulama). Erciyes Üniversitesi Sosyal Bilimler Enstitüsü, Yayınlanmamış Yüksek Lisans Tezi, Erciyes.

Baltaş, A. (2007). www.baltas-baltas.com/kaynakdergiyazi.asp?PRI=261\&SAYI=14 - 18k.

Barling J.,Weber, T., Kelloway, E.K. (1996). Effects of Transformational Leadership Training on Attitudinaland Financial Outcomes: A Field Experiment. Journal of Applied Psychology, 81(6), 827832.

Bayram, Ş. (2013). Liderlik Kavramı ve Liderlik Türlerinin İnovasyon Üzerindeki Etkileri. Gebze Yüksek Teknoloji Enstitüsü Sosyal Bilimler Enstitüsü.

Bennis, W. G. (1959). Leadership Theory and Administrative Behavior: The problem of Authority. Administrative Science Quarterly, 259-301.

Bush, T. (2007). Educational Leadership and Management: Theory, Policy, and Practice. http://www.ajol.info/index.php/saje/article/viewFile/25107/, Erişim Tarihi:10.09.2016.

Cascio, W. F. (2010). Managing Human Resources (8th Edition). New York: McGrawHill.

Ceylan A. (1997). Liderliğe Kurumsal Yaklaşımlar. 21.Yüzyılda Liderlik Sempozyumu Bildiriler Kitab1, Cilt: II, İstanbul.

Cheng, B. S.,Chou, L. F., Wu, T. Y., Huang, M. P., \& Farh, J. L. (2004). Paternalistic Leadership and Subordinate Responses: Establishing a Leadership Model in Chinese Organizations. Asian Journal of Social Psychology, 7(1), 89-117.

Cheong, M.,Spain, S.M., Yammarino, F.J., \&Yun, S. (2016). Two Faces of Empowering Leadership: Enabling and Burdening. The Leadership Quarterly, 1-15.

Conarroe R.R. (1989). Yönetimde 32 altın kural: İş hayatında nasıl daha başarılı olursunuz?. (çev: Yakut Güneri). İstanbul: İlgi Yayıncılık.

Çetin, N. G., Beceren, E. (2007). Lider kişilik: Gandhi. Süleyman Demirel Üniversitesi Sosyal Bilimler Enstitüsü Dergisi, 3(5), 110-132.

Davis, K. (1988). İşletmede İnsan Davranışı. (Çev. Kemal Tosun, Tomris Somay, Fulya Aykar, Can Baysal, Ömer Sadullah ve Semra Yalçın), İstanbul: 3.Baskı.

Decenzo, D. A., Robbins, S. P. (2010). Fundamentals of Human Resource Management. (4th Edition). Hoboken: Wiley. 
Aslan, Ş., Uyar, S. (2017). The perceptions of theory of characteristics leadership in health care managers.

International Journal of Social Sciences and Education Research, 3(2), 519-530.

Erçetin, Ş. Ş. (2000). Lider Sarmalında Vizyon. Ankara: Nobel Yayınları.

Eren, E. (1998). Örgütsel Davranış ve Yönetim Psikolojisi. İstanbul: Beta Yayıncılık, 5.Baskı.

Fındıkçı, İ. (2012). Bir Gönül Yolculuğu Hizmetkâr Liderlik. İstanbul: Alfa Yayınları.

Hedlund, J.,Forsythe, G.B., Horvath, J.A., Williams, W. M., Snook, S. \& Sternberg, R. J. (2003). Identifying and Assessing Tacit Konowledge: Understanding the Practical Intelligence of Military Leaders. The Leadership Quarterly, 14, 117-140.

Ireland, R.D., Hitt, M.A. (1999). Achieving and Maintaining Strategic Competitiveness in The 21st Century: The Role of Strategic Leadership. Academy of Management Executive, 13(1), 43-57.

Kağıtçıbaşı, Ç. (2000). Kültürel Psikoloji, Kültür Bağlamında İnsan Ve Aile. 2. Bask1, Sosyal Psikoloji Dizisi, İstanbul: Evrim Yayınevi ve Bilgisayar San. Ltd. Şti.

Kavrakoğlu, İ. Gedik, S. ve Balkır, M. (2002). Yeni Rekabet Stratejileri ve Türk Sanayisi. İstanbul: Tüsiad Yayınları.

Keçecioğlu, T. (1998). Örgüt Teorisinde Yenilikler. İstanbul: Beta Yayınları.

Kirkpatrick, S. A., Locke, E. A. (1991). Leadership: do traits matter?. Academy of Management Executive, 5(2), 48-60.

Koçel, T. (2011). İşletme yöneticiliği. İstanbul: Beta Yayıncılık.

Kouze, M. J., Barry Z. P. (2001). Geçmişe Bakıp Geleceğe Yönelmek. Exucutive Excellence Dergisi, 46.

Kozan, M. K. (1993). Cultural and Industrialization Level Influences on Leadership Attitudes for Turkish Managers. International Studies of Management \& Organization, 23(3), 7-17.

Kvale, S. (1995). Social Construction of Validity. Qualitative Inquiry, 1(1),19-40.

Lee, Y., Chang, Y. (2006). A Study on The Characters of Leader and Followers of Charismatic Leadership-the Example of Employees at a Port Authority. The Business Review, Cambridge, 5(1).

Likert, R. (1979). From Production-and Employee-Centerednessto Systems1-4. Journal of Management, 5(2), 147-156.

Lunenburg, F. C. (2011). LeadershipVersus Management: A Key Distinction-At Least in Theory. International Journal of Management, Business, and Administration, 14(1), 1-4.

Nahavandi, A. (2000). The Art and Science of Leadership. PrenticeHall, New Jersey.

Newstrom, J. W., Davis, K. (1993). Organizational Behavior: Human Behavior at Work. Mcgarw-Hill, New York.

Northouse, P. G. (2001). Leadership: Theory and Practice. (2 nd Edition), Sage Publications Ltd.,London.

Özer, A. K. (1997). Gerçekçi Yönetişim; Yönetici/Liderlik Modeli. İstanbul: Varlık Yayıncılık. 11-20.

Paksoy, M. (2012). Küreselleşme, Liderlik ve Liderlik Teorileri. (Editör: Celalettin Serinkan). Liderlik ve Motivasyon Geleneksel ve Güncel Yaklaşımlar. Ankara: Nobel, 1- 32.

Patton, 0. M. (1990). Qualitative Evaiuation an Research Methods. London: Sage Pub.

Robbıns, S. P., Judge, T. A. (2012). Organizational Behaviour. İstanbul: Nobel Yayıncılık.

Rost, J.C. (1991). Leadership for theTwenty-first Century. Praeger, New York. 
Aslan, Ş., Uyar, S. (2017). Sağlık yöneticilerinde liderlikte özellikler teorisi algılamaları. International Journal of Social Sciences and Education Research, 3(2), 519-530.

Russell, R.F., Stone, A.G. (2002). A Review of Servant Leadership Attributes: Developing A Practical Model. Leadership \& Organization Development Journal, 23(3), 145-157.

Schermerhorn, R .J. (1993). “Management for Productivity”.(4. Edition), Canada.

Şencan, M.N., İbicioğlu, H., Karabekir, M. (2015). Kadın Yöneticilerin Liderlik Özelliklerinin İncelenmesi: Türkiye'deki Kadın Rektörler Üzerine Bir İçerik Analiz. Süleyman Demirel Üniversitesi İktisadi Ve İdari Bilimler Fakültesi Dergisi, 20(1), 241-259.

Tannenbaum, S. I., Smith-Jentsch, K. A., \& Behson, S. J. (1998). Training Team Leaders to Facilitate Team Learning and Performance.

Uğurlu, O., Hovardaoğlu, S. (2011). Liderlik Davranışının Değerlendirilmesinde Liderin Cinsiyeti, Değerlendiren Kişinin Cinsiyeti ve Liderlik Stili Arasındaki İlişki. Türk Psikoloji Dergisi, 26 (68), 14-27.

Yukl, G. (2013). Leadership in Organizations. (8th Edition). New Jersey: Prentice Hall.

Zel, U. (2001). Kişilik ve Liderlik.(1. Baskı), Ankara: Seçkin Yayıncılık.

\section{Extended Abstract in English}

Aim and Importance: This study has been carried out toward studying whether or not the feature theory is applied at the present days. In addition, with this study, it has been targeted to study which features top management has.

The study has important in terms of what the features today's leaders hold, and that it touches on the features that a must have from the viewpoint of top management

Literature: Leadership, which is seen as an effective power in being able to cope with changes and eliminating reactions to be able to form against changes (Decenzo and Robbins, 2010), comes to our face as a concept, whose effect is undeniable in realizing either individual aims or collective aims (Alder, 2002). Leadership is expressed as ability to be able to direct a certain mass in the direction of aims (Bush, 2007). In the leadership process, in which influencing power is present (Erçetin, 2000), it is seen as obligatory that at least two people are present as affecting person and affected person (Paksoy, 2012). While Robbins and Judge ( 2012) defined leadership as the ability to affect and prompt a group of people, Yukl (2013) defined it as skill to be able to hold people together.

While there are some studies arguing that leadership is inherently existent, there are also some views that leadership is gained in either social environment or through education (Alder, 2002; Arslan and Durmuş, 2013). The dominant view is that one will not be borne as leader, but that individual can be inclined to leadership; and that he/she can develop leadership features, being affected from external factors (Çetin and Beceren, 2007).

According to the approach of features, there are some general and common features that leaders hold (Lee and Chang, 2006). Namely, in the approach of interest, leadership features possessed are seen as the most important factor affecting the process (Keçecioğlu, 1998; Nahavandi, 2000). What is underlying this approach, which can also be qualified as "Theory of Great Men", is the approach that history of human consists of the autobiographical stories of great men (Toprakçı, 2008). According to this theory, leadership features 
Aslan, Ş., Uyar, S. (2017). The perceptions of theory of characteristics leadership in health care managers. International Journal of Social Sciences and Education Research, 3(2), 519-530.

are inherent and people having these features emerge as leader in every environment ( $\mathrm{Na}-$ havandi, 2000). This approach is based on the thought that leaders succeed the extraordinary things thanks to their inherent features (Northouse, 2001). Leader has to hold physical features such as age, gender, handsomeness/beauty, appearance as well as abilities such as intelligence, knowledge, decisiveness, rhetoric, and personal features such as sincerity, honesty, and self-confidence (Yukl, 2013). Beside these features, empathy power, vision, becoming a good listener, and always becoming solution-oriented take place in the scope of leadership (Russell and Stone, 2002; Barling et al., 1996; Ireland and Hitt, 1999).

Method: In the study, the interview technique among qualitative study techniques was used. During the study, 8 health managers in 8 hospitals of 2 provinces in Central Anatolian Region were reached and 6 questions were raised them, which includes to evaluate the features. The participants are consist of the top managers such as hospital director, chief physician, general director, vice presidents in board of directors of hospital in the provinces of Konya and Eskişehir in Central Anatolia. In the selection of sample, a method was referred to, which consists of the participation of volunteers that is one of the methods not being probabilistically. The questions utilized in the study were selected from question pool obtained by reviewing international literature (Aslan, 2013; Bennis, 1959; Cheng, Chou, Wu, Huang, \& Farh, 2004; Kağıtçıbaş1, 2000; Kozan, 1993; Likert, 1979; Tannenbaum, Kimberly, \& Scott, 1998). As a result of literature review, the following questions were raised to the participative leaders.

"Which features should a good leader in your own sector have in your opinion?"

With which feature of yours do you think that you affect your employees the most?"

"If we asked your subordinates to define you, how would they define you?"

"What are the features, which everyone does not have but only the people, who can only become leader, in order?"

A view is put forward in such a way that a feature a successful leader must have is that leader is a person first realizing his/her own dream then their followers' dreams. Can you interpret whether or not you agree with this view together with their reasons?"

"A view is put forward in such a way that a feature a successful leader must have is that he/she is aware of his/her own features and knows to use his/her own skill and knowledge.Can you interpret whether or not you agree with this view together with their reasons?"

Conclusion and Discussion: In leadership approach of today, it is seen that especially communication and intelligence is emphasized. These two features are both present in the leaders and they are stated by them as features argued that the successful leaders must have. According to the feature theory, that leader has communication abilities from both organizational and individual aspects and thathe/she uses them in the direction of needs; that her/she has an intelligence over average are among the features that are necessary to be present in the leader (Kirkpatrick and Locke, 1991; Afkhami et al., 2007; Yukl, 2013).

Another feature the managers participating in the study have is that they have empathy power. In addition, the participants emphasizes that empathy ability has importance in the success of leader That a leader can collect his/her followers around long termed aims is seen in connected with that he/she can make empathy (Barling et al., 1996;Afkhami et 
al., 2007). That leader can understand one spoken to in every condition is considered as an action increasing motivation (Davis, 1988).

As a result of the study, that leaders realize their own dreams and their followers' ones is seen as necessity for success. When the literature is examined, also in feature approach, leader can use many values he/she has for the sake of realizing his/her image (Rost, 1991). The images leader has and want to realize can only be possible the authority and energy he/she has with his being able to transform into motivation on employees (Davis, 1988; Hedlund et al., 2003).

Becoming trustable, having empathy ability, giving importance moral values, being able to be solution-oriented, behaving as a guide, and realizing a management based on merit are also stated as the other features leaders must have. According to the theory of feature approach, a leader have these features put in order by managers more than the other individuals /(followers) have ) Barling et al., 1996; Ceylan, 1997; Conarroe, 1989; Lunenburg, 2011).

As a conclusion, today's leaders maintain the expression that the element making a person leader is his/her features" (Aslan, 2013). 